Alma Mater Studiorum - Università di Bologna DEPARTMENT OF ECONOMICS

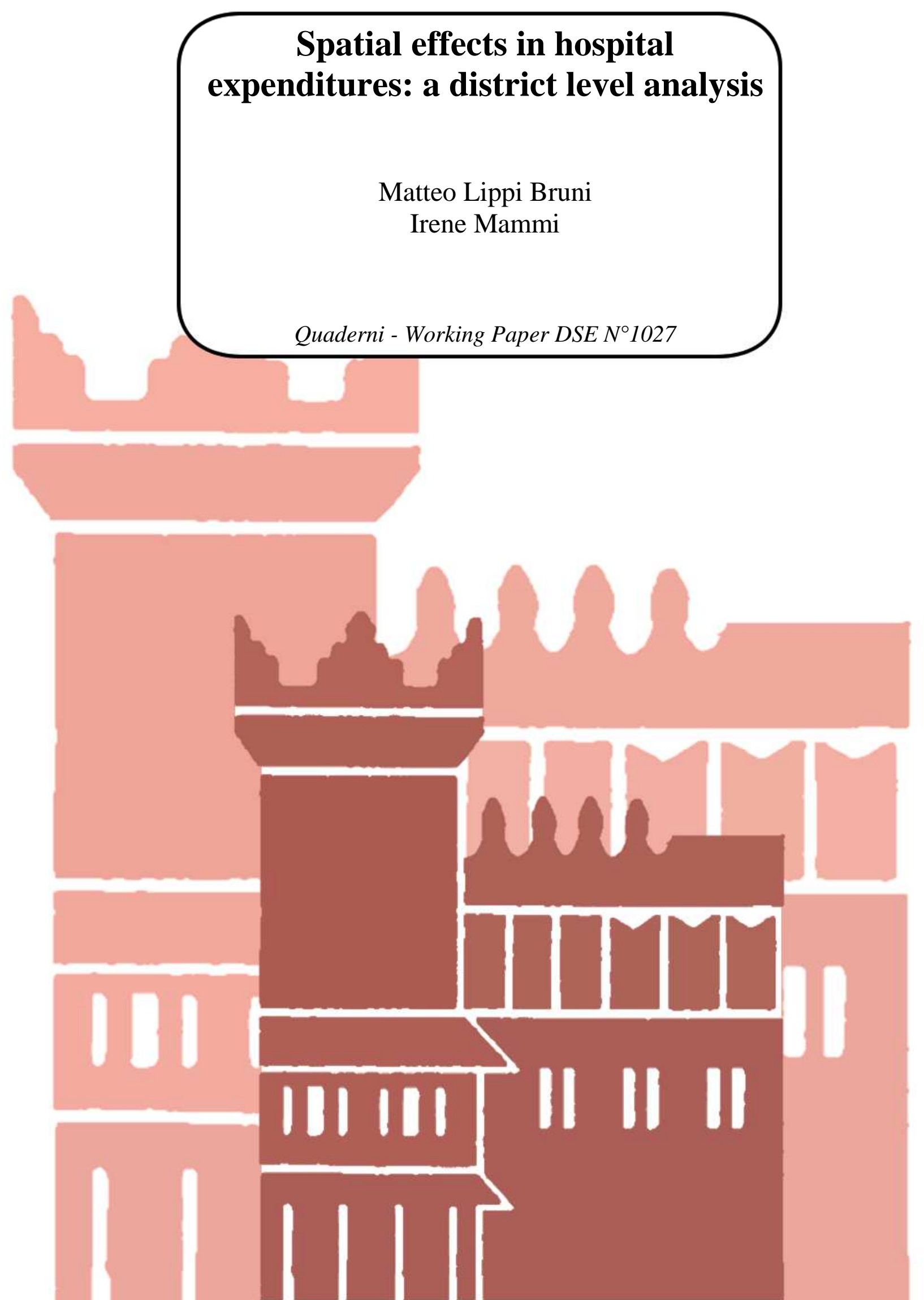




\title{
Spatial effects in hospital expenditures: a district level analysis
}

\author{
Matteo Lippi Bruni ${ }^{\text {a1 }}$; Irene Mammi ${ }^{\text {a }}$ \\ Department of Economics, University of Bologna, \\ Piazza Scaravilli, 2 40126, Bologna (Italy)
}

\begin{abstract}
Geographical clusters in health expenditures are well documented and accounting for spatial interactions may contribute to properly identify the factors affecting the use of health services the most. As for hospital care, spillovers may derive from strategic behaviour of hospitals and from patients' preferences that may induce mobility across jurisdictions, as well as from geographically-concentrated risk factors, knowledge transfer and interactions between different layers of care. Our paper focuses on a largely overlooked potential source of spillovers in hospital expenditure: the heterogeneity of primary care providers' behaviour. To do so, we analyse expenditures associated to avoidable hospitalisations separately from expenditures for highly complex treatments, as the former are most likely affected by General Practitioners, while the latter are not. We use administrative data for Italy's Region Emilia Romagna between 2007 and 2010. Since neighbouring districts may belong to different Local Health Authorities (LHAs), we employ a spatial contiguity matrix that allows to investigate the effects of geographical and institutional proximity and use it to estimate Spatial Autoregressive and Spatial Durbin Models.
\end{abstract}

Key words: Hospital expenditures, spatial effects, panel data, institutionally-clustered data.

JEL codes: I11, R12, C23

\section{Acknowledgments:}

We are strongly indebted to Vincenzo Atella, Federico Belotti, Domenico Depalo and Andrea Piano Mortari for providing the Stata programs used in the analysis, and we thank the participants at the Health Economics Study Group held at Lancaster University, especially our discussant James Gaughan, for their useful comments. The paper is part of a research project funded by the Health Department of Emilia-Romagna, Italy, that also provided the data and whose support is gratefully acknowledged. We thank Eugenio Di Ruscio who coordinated the project for the Department of Health. The work reflects exclusively authors' opinions and does not involve the above mentioned institution. Usual disclaimers apply.

\footnotetext{
${ }^{1}$ Corresponding Author: Matteo Lippi Bruni (Tel. +39 051 2098145) .

E-mail addresses: matteo.lippibruni2@unibo.it (M. Lippi Bruni); irene.mammi@unibo.it (I. Mammi)
} 


\section{Introduction}

Since the seminal contributions by Wennberg and Gittelsohn (1973), regional and small area variations in health expenditures have received a great deal of attention and, by now, ample empirical evidence shows that expenditures may vary substantially across practices, municipalities and regions. More recently, the health economics literature has documented the presence of spatial clustering implying that geographically close observations often display more similar patterns compared to those located far apart (Skinner 2011). Applying spatial econometrics methods, an increasing number of contributions has investigated spatial interactions in the healthcare sector focusing mainly on spillovers across regions or neighbouring jurisdictions (Costa-Font and Moscone 2009, Yu et al. 2013). This stream of works has covered a broad range of expenditure sources, including regional (Costa-Font and Pons-Novell, 2007), hospital (Bech and Lauridsen 2008), pharmaceutical (Ehlhert and Oberschachtsiek, 2014), mental health (Moscone et al, 2007), general practice (Bech and Lauridsen, 2009a) and outpatient expenditures (Bech and Lauridsen, 2009b). Overall, spatial dependence is found to generate a sizeable impact on the patterns of expenditures and to significantly affect the estimates of their determinants.

As for hospital expenditures, the main causes of spatial spillovers have been identified, on the supply side, in the competition across hospital providers and in the knowledge transfer influencing local practice styles, while, on the demand side, in the heterogeneity in patients' health profiles and preferences (Gravelle et al. 2014; Baltagi and Yen 2014). More recently, a different stream of works has focused on primary care as a key channel that affects hospital utilisation (e.g. Martin et al. 2010; Dusheiko et al. 2011; Gibson et al. 2013). This attention is a consequence of the increasing policymaker's attempt to strengthen the role of General Practitioners (GPs) as promoters of an efficient use of health services through appropriate referrals to inpatient or outpatient services (Bech and Lauridsen, 2009; Beales and Smith 2012).

The main aim of the present paper is to fill a gap in the literature by building a bridge between the contributions that investigate spatial interactions in hospital utilization and the studies on the influence of primary care on intensity and appropriateness in the use of the hospital. To do so, we adopt spatial econometrics methods to analyse clustering in per-patient hospital expenditures and we focus in particular on the influence produced by geographical differences in primary care organization. As long as local policies and conditions affect GPs' activity and gatekeeping to secondary care, the variety of primary care policies often observed across jurisdictions can contribute to generating spatial correlations in hospital expenditures by affecting referral patterns. 
Therefore, for properly assessing the determinants of hospital expenditures, it is important to account for the spillovers across areas characterized by differences in the governance of primary care and in the associated initiatives, as this will allow policymakers to better evaluate the impact and effectiveness of the existing policies and to properly target their interventions.

A second relevant issue addressed in our analysis is the distinction between geographical and institutional proximity. In contexts where local jurisdictions enjoy a large degree of autonomy, and in particular when a multi-tier government organisation is involved, not only geographical distance but also institutional borders have to be considered among the factors that may significantly affect the intensity of spillover effects (Arbia et al. 2009; Atella et al. 2014). As for the first issue, the influence of common epidemiological and supply side characteristics, together with imitation patterns are expected to be stronger for closer units compared to more distant ones. As for the second issue, since subjects in the same jurisdiction face the same regulatory framework and incentive structure, expenditures for those units located within the same borders are expected to follow more similar patterns compared to those in different jurisdictions.

We use administrative data from Italy's Region Emilia Romagna to jointly investigate the impact of geographical and institutional proximity on hospital expenditures. In the Italian National Health System (NHS), each Local Health Authority (LHA) is subdivided into Health Districts (HDs) which are responsible for the implementation of primary care policies while LHAs retain a role of coordination. Therefore, we consider expenditures aggregated at the district level, separately considering spatial spillovers generated across HDs in different LHAs, from those among districts belonging to the same LHA. In order to assess whether the organisation and characteristics of primary care affect spatial patterns in hospital expenditures, we perform separate analysis for episodes of potentially inappropriate utilisation of the hospital and for those associated to complex medical treatments. By doing so, we treat separately those cases more likely to be affected by the access to effective primary care services from those treatments that are not expected to be influenced by them.

\section{Institutional setting}

The Italian NHS is organised on a regional basis with the National Government retaining the right to set the basic principles and Regional Governments enjoying a large autonomy in financing and organising the delivery of care (Lo Scalzo et al. 2009). Within each region, Local Health Authorities (LHAs) are in charge of delivering care to the resident population and are mainly financed by the Regional Health Department using a capitation formula adjusted for the demographic composition of the population. 
As for hospital care, three main types of facilities can be identified. The largest, high qualified centres, including also all University Hospitals, enjoy the status of autonomous Hospital Trusts (HTs). The HT status is held also by other third level facilities, specialised in assistance and medical research typically dealing with a single clinical area and acting as a reference centres at the regional and national level. In most Regions, all other hospitals are directly run by the LHAs and they include medium-sized hospitals located in urban contexts (type A Hospitals), and community hospitals located in small towns or in rural contexts (type B Hospitals). The main funding source for HTs is a prospective payment scheme based on Diagnosis Related Groups (DRGs) but DRG tariffs play a relevant role in budget setting also for the LHA-run hospitals (Cappellari et al., 2014). Indeed, the budget for both type A and type B hospitals is agreed with the LHA according to the volume of activity produced in the previous year, and the value of the services provided is quantified using DRG tariffs that take into account the different cost structures across types of hospitals. In addition to that, both HTs and LHA-run centres receive ad hoc funding for specific programs and objectives, in particular to cover the costs of clinical areas with a high fixed cost component and of services of general interest such as emergency care. Hospital care is free at the point of need and is accessed either through the Emergency Department or through a referral by patient's own GP. Patients can choose any public or privately accredited facility in the country: mobility is in fact allowed not only across LHAs but also across Regions. The empirical evidence shows that interregional mobility involves a non-negligible share of patients and concentrates mainly on highly specialised treatments (Fabbri and Robone, 2010; Balia et al., 2014) Moreover, differences in waiting times for eligible treatments together with free patients' mobility generate incentives to shop around in search of faster responses not only for outpatient but also for inpatient services (Fattore et al., 2013).

Access to primary care is free of charge. GPs are independent entrepreneurs contracted by the Regional Government and are responsible for providing ambulatory services and for referring their patients to specialist and hospital providers. Registration with a GP is compulsory and the choice of the physician can be modified at any time, though the empirical evidence suggests that switches are infrequent (Italian Ministry of Health, 2010). Community services fall under the main responsibility of Health Districts (HDs) that are sub-entities of LHAs. The HD's management bodies are appointed by the LHA director as LHAs are in charge of financing HDs' activity and of planning and coordinating local health policies, in particular for the component that relates to the connection between primary and secondary care. GPs operate in single handed practices, although there is a trend towards the creation of professional networks among family physicians in order to favour cooperation on dimensions that include substitution in case of absence and information sharing about clinical best practices (Compagni et al., 2014; Lippi Bruni et al. 2014). The integration of physicians' activity can 
be further extended as GPs may choose to share medical equipment, nursing staff and premises. However, even in these cases, each citizen is registered with a specific physician and not with the network as a whole. Hence, the list of enrolled patients is univocally attributed to a specific physician. GPs are paid for the most part using a capitation scheme contracted at the national level. Remuneration can be topped up by additional payments agreed at the district level. These transfers are usually aimed at incentivising high quality of care for specific conditions, including chronic diseases (Fiorentini et al. 2011; lezzi et al. 2014) and physicians' adherence to clinical guidelines and to cost containment strategies defined at the local level.

\section{Contextual framework}

The path-breaking work on social interactions by Manski (1993) provides a useful framework to classify the possible sources of spillovers across neighbourhoods or jurisdictions. Three types of effects are typically referred to in the literature: endogenous, exogenous and correlated effects. The endogenous effects consist of the changes in the behaviour of a given subject in response to the choice of the others; the exogenous/contextual effects follow from similar exogenous characteristics among neighbouring units; the correlated effects consist of the influence of unobserved features either related to individual characteristics or to the common environment shared by contiguous units $^{2}$. In the context of the present study, all these effects can be thought as potentially affecting hospital expenditure patterns. As for the links between primary and secondary care, endogenous effects can be associated in first place to imitation patterns in the adoption of successful policies and best practices among health districts as well as among physicians. Such process of knowledge transfer is likely to be more intense for contiguous units, thus affecting professional behaviour and local practice styles, which in turn may influence utilisation rates of the hospital and the associated expenditures. As for the contextual effects, expenditures in neighbouring HDs may display high spatial correlation because, for example, an hospital centre serves more than one district ${ }^{3}$. In addition to that, hospitals might also devote effort to attract patients from different LHAs when tariffs are set above the marginal cost of treatment. Since the propensity of patients to shop around for higher quality or more timely responses to their needs quickly decreases with distance (Lippi Bruni et al. 2008), geographical proximity is likely to strongly affect the empirical relevance of these processes. However, also other institutional features of the NHS, characterised by a multilevel

\footnotetext{
${ }^{2}$ Manski (1993) discusses in detail the impossibility to separately identify the three types of effects, unless one is ready to make very strong assumptions, an issue known in the literature as the "reflection problem".

${ }^{3}$ Moscone et al. (2007) refer to this feature of health care systems in the context of spatial analysis as "the shared resource hypothesis".
} 
organisatio, may contribute to spatial clustering. Indeed, the patterns described above may differ in intensity according to whether geographically contiguous units belong to the same upper layer level of care (here, the same LHA) or not.

Overall, the vertical and horizontal relations that characterise both the institutional and professional level generate overlaps of planning responsibilities and interdependencies which may lead to a considerable geographical heterogeneity health care policies - including those implemented at the primary care level- across jurisdictions and to clusters in professional connections among physicians. To the extent that the organisation of primary care and the nature of professional relationships affect referrals to the hospital, all these factors can potentially induce spillovers across practices and health jurisdictions which should be properly accounted for in empirical analysis.

From a positive perspective, neglecting the impact of spatial spillovers may generate spurious effects on the coefficients of the determinants of hospital utilisation and introduce a bias in the estimated impact of the explanatory variables. From a normative perspective, as policymakers are increasingly interested in monitoring performance of low tier jurisdictions- including their capacity to limit the degree of inappropriateness in hospital utilisation - failing to control for spatial spillovers and for the specific role of institutional borders may lead to a flawed evaluation.

\section{The data}

We use administrative data from the Italian Region Emilia Romagna for the period 2007-2010 and consider expenditures aggregated at the district level. The estimating sample covers $3,353,824$ citizens (aged 14 or above) who are followed by 2,780 GPs operating in 38 Health Districts ${ }^{4}$. The data used in the study are drawn from administrative databanks collected by the regional Department of Health, partly referring to of primary care and partly to hospital care.

As regards the use of hospital services, we exploit Hospital Discharge Records (HDRs) which allow to track all hospitalisations for all patients residing in the Region, irrespectively of whether they are treated in an hospital located within the Region or outside. Patients' hospital expenditure is computed attributing to each episode the monetary value expressed by the tariff recognised by the Regional Department of Health if the patient is treated by an hospital within the Region, or by the national tariff if he is treated in a different region ${ }^{5}$. The tariff depends on the DRG category and on

\footnotetext{
${ }^{4}$ The figures reported for patients and GPs refer to the yearly average over the observation period.

${ }^{5}$ National tariffs are on average lower than the Emilia Romagna's ones, because of intense negotiations that took place at the national level over the years aimed at discouraging strategic behaviour among regions trying to attract patients from other areas of the country.
} 
the type of hospital, with $\mathrm{HT}$ and type $\mathrm{A}$ hospitals receiving a higher compensation than type $\mathrm{B}$ hospitals in recognition of the higher fixed costs they face compared to community hospitals. The baseline DRG tariff is augmented in case of complications or when the length of stay exceeds a predefined threshold. For each hospitalisation, the information on the tariff, comprehensive of the aforementioned possible adjustments, is included in the HDRs and it is used to construct our dependent variable. For each district in each year we sum the tariffs of all hospitalisations of all patients above 18 who reside in the district, and we then compute the per-patient average expenditure for acute hospital care at the district level which is the dependent variable for our model.

In order to evaluate the role of primary care services in generating spatial spillovers in the use of hospital services, we consider expenditures for hospitalisations expected to be influenced by GP's activity separately from hospital expenditures for largely unaffected by GP's decisions. For this purpose, we include in the first group the episodes of potentially inappropriate utilisation of the hospital, as identified by the Regional Health Department of Emilia Romagna by means of a list of Diagnosis Related Groups (DRGs) at risk of inappropriate hospitalisation. These are conditions whose frequency can be reduced by effective primary care provision. The second group encompasses highly complex treatments, whose occurrence is deemed to fall beyond the control of family physicians. To the extent that geographical heterogeneity in the delivery of primary care contributes to spatial clustering in hospital expenditures, local spillovers are expected to be larger for avoidable hospitalisations compared to complex treatments, that are influenced by utilization of primary care relatively less.

The descriptive statistics for the two dependent variables are reported in Table 1 for each year covered in our study.

\section{TABLE 1 HERE}

The data indicate that hospitalisations for potentially avoidable episodes generate an amount of expenditures that ranges roughly between one third and one half of the expenditures associated to highly complex treatments, with the former accounting for around $15 \%$ and the latter accounting for $38 \%$ of total expenditures over the four-year time span. Over time, we record a slight downward trend in expenditures for complex treatments, while potentially inappropriate expenditures show a remarkable increase between 2008 and 2009. For estimation purposes both dependent variables are log transformed. 
As for the explanatory variables, a first set of controls, measured at the district level, accounts for the characteristics and organisation of GPs' practices. These include the average GP's seniority (GP_seniority), the share of associated practices (share_assoc_GPs), the share of practices with nursing staff (share_nurse) or administrative collaborators (share_collaborator). A second group of indicators captures the socio-demographic composition of the health districts with the shares for age classes (the group 14-36 is taken as reference), the proportion of males (share_males) and of foreigners (share foreigners) entering as regressors.

Additional information is exploited to control for the features of the local health care systems and include: the density of GPs in each HD (num_GP); the per capita number of hospital beds (beds_LHA), of physicians, nurses and clerks employed by the local LHAs (doctors_LHA, nurses_LHA, clerks_LHA, respectively); the raw LHA mortality rate (mort_LHA). We add also a dummy for the presence of $\mathrm{HT}$ in the HD (HD with $H T)$ and a dummy for the presence of a type A hospital (HD with type $A$ hosp). Finally, geographical features are controlled for with a dummy for districts located in partially or totally mountainous areas (mountainous area), while local socio-economic conditions are proxied by per-capita taxable income (income_HD) measured at the HD level. All variables, whose descriptive statistics are reported in Table 2, are log-transformed except for the dummy variables.

\section{TABLE 2 HERE}

\section{The empirical methodology}

\subsection{The standard spatial panel regression models}

The standard linear panel data models assume the absence of cross-sectional correlation among the units of observation so that they are not suitable to account for spatial dependence among geographical units. In fact, ignoring the potential spatial dependence either in observable or unobservable variables may bias the estimates of the coefficients of interest (LeSage and Pace, 2009).

A proper way to deal with spatial spillovers, either exogenous or endogenous, is to estimate spatial panel data models which allow to incorporate spatial dependence (Elhorst, 2003, 2014) by means of the inclusion of spatially autocorrelated disturbances and/or spatially lagged dependent and control variables. The inclusion of the spatially lagged dependent variable allows for endogenous spillover effects, that is for a causal link between the dependent variables of two different geographical units (feedback effect). On the other hand, the inclusion of spatially lagged regressors allows for potential exogenous spatial interaction effects. In this way it is possible to test whether a change in a regressor in a given geographical unit affects the outcome variable of the neighbouring units. 
Allowing for autocorrelated errors permits to take into account spatial interaction effects in unobservables among units.

A general formulation of the spatial panel model reads as:

$$
\begin{gathered}
\boldsymbol{Y}_{\boldsymbol{t}}=\rho \boldsymbol{W} \boldsymbol{Y}_{\boldsymbol{t}}+\boldsymbol{X}_{\boldsymbol{t}} \boldsymbol{\beta}+\boldsymbol{W} \boldsymbol{X}_{\boldsymbol{t}} \boldsymbol{\theta}+\boldsymbol{\mu}+\alpha_{t} \boldsymbol{\iota}_{\boldsymbol{N}}+\boldsymbol{u}_{\boldsymbol{t}} \\
\boldsymbol{u}_{\boldsymbol{t}}=\lambda \boldsymbol{W} \boldsymbol{u}_{\boldsymbol{t}}+\boldsymbol{\varepsilon}_{\boldsymbol{t}}
\end{gathered}
$$

where $\boldsymbol{Y}_{\boldsymbol{t}}$ includes the $N \times T$ observations on the dependent variable, $\boldsymbol{X}_{\boldsymbol{t}}$ is a matrix of regressors, $\boldsymbol{\mu}$ is a vector of time-invariant spatial effects that may be either fixed or random, $\alpha_{t}$ is a vector of time effects either random or fixed and $\boldsymbol{u}_{\boldsymbol{t}}$ is the vector of disturbances. The crucial feature of such model is the presence of the $N \times N$ symmetric weight matrix $\boldsymbol{W}$ that summarises the pairwise spatial relationships between the units in the sample. The choice about the structure of the spatial weight matrix $\boldsymbol{W}$, specifically targeted on the purposes of our analysis will be extensively treated in a dedicated section. As discussed in Elhorst $(2010,2014)$, the spatial autoregressive term $\boldsymbol{W} \boldsymbol{Y}_{\boldsymbol{t}}$ accounts for endogenous spatial interaction effects among the dependent variable across different spatial units; the inclusion of spatially lagged regressors in $\boldsymbol{W} \boldsymbol{X}_{\boldsymbol{t}}$ allows for exogenous spatial interactions among the regressors while $\boldsymbol{W} \boldsymbol{u}_{\boldsymbol{t}}$ allows for spatial correlations among the disturbances. The assumptions on which interactions effects can be excluded from the model, and therefore on which parameters (the spatial autoregressive coefficient $\rho$, the vector $\boldsymbol{\theta}$ including the coefficients of spatially lagged regressor or the spatial autocorrelation coefficient $\lambda$ ) should be set to zero, determine alternative specifications of the spatial panel model to be estimated. In what follows we consider three specifications of the model in (1) and (2): assuming that $\rho=\boldsymbol{\theta}=\lambda=0$, we are back to the standard linear panel model with no spatial effects that we estimate by Pooled OLS, by fixedeffects (FE) o by random-effects (RE) estimators; we then estimate a Spatial AutoRegressive (SAR) model which assumes both $\boldsymbol{\theta}=\mathbf{0}$ and $\lambda=0$ so that only endogenous interaction effects take place; finally, we only assume that $\lambda=0$ and we estimate a Spatial Durbin Model (SDM) which allows for both endogenous and exogenous spatial interactions. The SAR model comes out as the most natural choice when we are interested in exploring spatial spillovers in hospital expenditures, since we expect in this context the endogenous interactions to be particularly significant. By estimating a SDM we also include spatially lagged regressors which, as discussed in LeSage and Pace (2009), control for the omission of relevant variables correlated with the included covariates. A further advantage of the SDM specification is that it provides consistent estimates even when the true model is a SAR. As in our analysis the sample includes the whole population of interest, namely all the Health Districts in the Region, and the observations cannot be seen as drawn from a larger population, the fixed effect specification is the most appropriate one for the model with spatial effects. Furthermore, the 
fixed-effects specification allows for a correlation between the regressors and the individual-specific effects, that might actually be a concern is such framework.. Throughout our analysis we will therefore assume the spatial effects in $\boldsymbol{\mu}$ to be deterministic. The Maximum Likelihood (ML) estimates of the model in equations (1) and (2), either in the SAR and in the SDM specifications, are obtained by using the xsmle command in Stata.

\subsection{The spatial weight matrix $W$}

The spatial weight matrix $\boldsymbol{W}$ captures the connections among the spatial units observed in the sample. $\boldsymbol{W}$ has to be specified prior to the estimation of the model and a wide range of alternative structures are potentially available for it, in order to weigh the spatial observations based, for instance, on geographical, institutional, economic or social proximity or on distance. Each cell $w_{i j}$ of the $\boldsymbol{W}$ matrix reflects the intensity of the spatial interaction between unit $i$ and unit $j$, or, stated differently, the spatial influence of unit $j$ on unit $i$. By convention, $w_{i i}=0$, so that the $\mathbf{W}$ matrix has a zero diagonal.

The first part of our empirical analysis follows the standard approach of the literature and thus implements an estimation strategy based on a single weighting matrix. Given the feature of the institutional context that is characterised by a two-tier level of jurisdictions with HDs nested into LHAs, one can consider two alternative specifications of the $\boldsymbol{W}$ matrix. The first one is based on mere geographical contiguity among spatial entities, as captured by shared borders between two neighbouring HDs. In this case, the cell $w_{i j}$ assumes value of 1 if the $i^{t h} \mathrm{HD}$ shares a common border with the $j^{\text {th }} \mathrm{HD}$ and 0 otherwise, irrespectively of whether they belong to the same LHA or not. Here, when estimating a SAR or SDM model, for each HD the spatially lagged dependent variable is a weighted average of the health expenditures in the neighbouring HDs. The second specification extends the notion of "neighbourhood" adopting a metrics that includes also the institutional proximity among HDs alongside the geographical one. In this case, we slightly modify the previous weight matrix as follows: the $\boldsymbol{W}$ matrix has cell $w_{i j}=1$ not only if $\mathrm{HD} i$ and $\mathrm{HD} j$ share the same border but also if they belong to the same LHA, and zero if two HDs neither have a common border nor belong to the same LHA. The rationale behind the specification of this second weight matrix is that HDs that belong to the same LHA are subjects to the same institutional constraints and are affected by the same healthcare policies promoted by the LHA, though they might not have any border in common. As standard in the literature, we row-standardise the weight matrix so that the weights are always in the range 0-1 and the spatially lagged variables are a weighted average of the neighbours' observed values for those variables. 


\subsection{Accounting for institutional constraints}

In order to gain further insights on the impact of institutional constraints on spatial patterns in expenditures, it is useful to disentangle the sources of spatial dependence when the geographical units of interest are subject to different institutional constraints. In a recent contribution which extends Lacombe (2004), Atella et al. (2014) propose an empirical approach designed for this purpose. They exploit two different contiguity matrices that result from the partition of a standard contiguity matrix denoted by $\boldsymbol{W}$ : the first one, labeled within matrix, defines contiguity among units that are subject to the same institutional setting; the second one, labeled between matrix, defines contiguity among spatial entities which share a common border but that belong to different higherlevel jurisdictions. The cell $w_{i j}^{w}$ of the within matrix, denoted by $\boldsymbol{W}_{\boldsymbol{w}}$, takes value of 1 if entity $i$ and entity $j$ share a common border and are subject to the same jurisdiction and 0 otherwise. In the between matrix $\boldsymbol{W}_{\boldsymbol{b}}$, the cell $w_{i j}^{b}$ is 1 if entity $i$ and entity $j$ share a common border but belong to different LHAs and 0 otherwise.

Such approach is particularly appealing for the purposes of our work and given the institutional framework that characterizes the Italian NHS. Therefore, in order to disentangle the two alternative sources of spatial dependence, we partition the contiguity matrix $\boldsymbol{W}$ discussed in the previous section into the two matrices $\boldsymbol{W}_{\boldsymbol{w}}$ and $\boldsymbol{W}_{\boldsymbol{b}}$. Following Atella et al (2014), we disentangle the endogenous from the exogenous interaction effects in a within and a between component, so that a modified version of the model in (1) encompassing the partition into the two sources of dependence becomes:

$$
\boldsymbol{Y}_{\boldsymbol{t}}=\rho_{w} \boldsymbol{W}_{\boldsymbol{w}} \boldsymbol{Y}_{\boldsymbol{t}}+\rho_{b} \boldsymbol{W}_{\boldsymbol{b}} \boldsymbol{Y}_{\boldsymbol{t}}+\boldsymbol{X}_{\boldsymbol{t}} \boldsymbol{\beta}+\boldsymbol{W}_{\boldsymbol{w}} \boldsymbol{X}_{\boldsymbol{t}} \boldsymbol{\theta}_{\boldsymbol{w}}+\boldsymbol{W}_{\boldsymbol{b}} \boldsymbol{X}_{\boldsymbol{t}} \boldsymbol{\theta}_{\boldsymbol{b}}+\boldsymbol{\mu}+\alpha_{t} \boldsymbol{\iota}_{\boldsymbol{N}}+\boldsymbol{u}_{\boldsymbol{t}}
$$

We estimate the model in (3) following both a fixed-effect SAR specification and a fixed-effect SDM model. $\boldsymbol{W}$ can be specified according to the two formulations discussed in the previous section and accounts for either pure geographic contiguity or geographic/institutional proximity; in this extension, such matrix is now partitioned in the two components. The $\boldsymbol{W}_{\boldsymbol{b}}$ is the same in both cases and the cells have values $w_{i j}^{b}=1$ when two HDs have a common border but belong to different LHAs. As for the within matrix, $w_{i j}^{w}=1$ for districts that share a border and belong to the same LHA when a strict criterion of geographical proximity is adopted; instead, when we also account for the institutional proximity of non-adjacent HDs, $w_{i j}^{w}=1$ in the case that two districts are in the same LHA no matter whether they share a common border. The model in (3) is estimated in Stata exploiting the user-written command spm. 


\section{Results}

Our empirical strategy follows three steps. We start by estimating for both dependent variables a standard linear panel data model that does not account for spatial correlation across observations by Pooled OLS, FE and RE estimators (Table 3).

\section{TABLE 3 HERE}

The results obtained at this stage serve as a benchmark for a first assessment of the implications of failing to take into account potentially relevant characteristics of the data at hand, such as the presence of spatial patterns, when evaluating the determinants of hospital expenditures.

As a second step, we specify our econometric model in such a way to account for spatial correlation across observations. In particular, we consider a fixed-effect SAR and a fixed-effect SDM model specification and, at this stage, we exploit a single weight matrix - which may be $\boldsymbol{W}, \boldsymbol{W}_{\boldsymbol{w}}, \boldsymbol{W}_{\boldsymbol{b}}$ where $\boldsymbol{W}$ may based on two slightly different definitions of contiguity discussed in detail in section 5.2 and consequently also the partition in the two matrices $\boldsymbol{W}_{\boldsymbol{w}}$, and $\boldsymbol{W}_{\boldsymbol{b}}$. Since the main aim of the paper is to assess the overall relevance of spatial spillovers in expenditures across districts, we first present and discuss the results for the spatial autoregressive component, namely the estimates of the coefficients $\rho$ in model (1).

\section{TABLE 4 HERE}

Table 4 reports the estimates for the spatial autoregressive coefficients for the two dependent variables introduced in previous sections. The default case corresponds to a single matrix where proximity is defined according to a geographical criterion, i.e. whether two HDs share a common border. The subscript_LHA indicates a departure from the default case and an institutional metrics is added to the geographical one, such that are classified as "neighbours" also all the HDs in the same LHA irrespectively of whether they share a border or not.

For potentially inappropriate expenditures, the estimates of the spatial effects generally come out positive and statistically significant, the only exception being the case in which the only matrix used is $\boldsymbol{W}_{\boldsymbol{b}}$. The large magnitude of the coefficients, ranging when significant between 0.32 and 0.50 , points to the presence of strong interaction effects among HDs. The comparison between SAR and SDM results when exploiting $\boldsymbol{W}$ provides evidence that, once we control also for spatially lagged regressors and we allow for exogenous spatial effects, the estimated endogenous interactions are smaller, though the coefficient is still about 0.3. Moving to the "augmented" weight matrix, we find evidence of stronger interactions among HDs than in the case in which only geographic proximity is 
considered. The spatial effects estimated exploiting $\boldsymbol{W}_{\boldsymbol{w}}$ are, in the case of SDM, very close to those estimated using the augmented $\boldsymbol{W}$, while no "between" spatial effects emerge: this evidence points to the finding that in this context stronger spatial interactions among HDs intervene when they belong to the same LHA.

When we consider expenditures associated to highly complex DRGs, the estimated spatial effects are weaker and in most cases not significant, pointing to a limited evidence of spatial spillovers for outcomes that are not expected to be affected by differences in primary care organization. Interestingly, in the only case when the spatial autoregressive coefficient is significant at the $5 \%$ level, the estimated sign is negative: this confirms that the nature of the interactions across jurisdictions for the two type of treatments is very different.

Overall, these results are consistent with the idea that heterogeneity in primary care activity may represent an important source of spatial clustering for hospital expenditures. Indeed, when controlling for a set of primary care characteristics, the hospital expenditures expected to be sensitive to GP decisions display a strong spatial correlation.

Table 5 presents the results for the SAR and SDM specifications for the case of a single weight matrix. In the table, we report the estimates for the coefficients $\rho, \boldsymbol{\beta}$ and $\boldsymbol{\theta}$ in model (1), as well as the total spatial effects disentangled also in the direct and indirect components.

\section{TABLE 5 HERE}

The explanatory power of the control variables included in the analysis appears weak for both the dependent variables considered. Partial exception is the demographic composition of the district population where a higher share of individuals aged between $36-50$ is positively associated to expenditure levels, in particular when we consider the direct effect measured for inappropriate episodes. Higher average GP seniority is in some cases significantly associated to lower expenditures, both for inappropriate and complex conditions, and again the effect emerges as significant for the direct effects.

Finally, the third step of the analysis consists of the estimation of the model in (3) using two weights matrices. Table 6 reports the estimates of the spatial autoregressive coefficients $\rho_{w}$ and $\rho_{b}$ in model (3) for the SAR and SDM specifications and both the dependent variables when two spatial weights matrices are used at the same time.

TABLE 6 HERE 
When we employ the double matrix, for potentially inappropriate expenditures both the within and the between spatial effects are estimated as large in magnitude and highly statistically significant. While we find no relevant differences in the estimated effects according on whether we take the standard or the "augmented" weight matrix to be partitioned, it is particularly interesting to consider how the spatial interactions can be disentangled in a within and a between component. Taking the SDM results as the benchmark since the estimates are consistent also when the true DGP is a SAR (LeSage, 2014), we find that the interactions within the same LHA account for about three fourths of the total endogenous spillover; while one fourth can be attributed to interactions between neighbouring areas belonging to different institutional settings, as defined by the LHAs. The absence of spatial spillovers for expenditures associated to high-complexity treatments emerge here as clear-cut. None of the spatial autoregressive coefficients, in neither components, comes out as statistically significant. Finally, in Table 7 we present the estimates of the coefficients $\rho_{w}, \rho_{b}, \boldsymbol{\beta}, \boldsymbol{\theta}_{\boldsymbol{w}}, \boldsymbol{\theta}_{\boldsymbol{b}}$ for the SAR and SDM specifications of the model in (3).

TABLE 7 HERE

\section{Conclusions}

The present paper aimed at empirically assessing the presence of spatial effects on hospital expenditures at the district level. Its main purpose was to investigate the contribution to geographical clustering in expenditures of primary care, as it represents a largely overlooked, albeit important, potential source of heterogeneity across health jurisdictions which may significantly affect also the intensity and degree of appropriateness of hospital utilisation. Moreover, we exploit an empirical strategy designed to separately evaluate the effects of spatial spillovers within and between healthcare jurisdictions and to address the influence of both geographical and institutional proximity among health districts.

We conduct a district level analysis since, in the Italian NHS, this is the institutional level in charge of designing and coordinating health policies in primary care. We separately considered two types of hospital expenditures: those associated to episodes of potentially inappropriate use of hospital services and those associated to complex medical treatments. Such choice is based on the conjecture that the former group of expenditures is affected by the delivery of effective primary care services, preventive measures and accurate gatekeeping, as the recourse to the hospital is deemed to be potentially avoidable in these cases. On the contrary, the latter type of expenditures relates to conditions that typically fall beyond the control of community services, including primary care providers. 
Our main findings indicate that spatial effects are significant and large in magnitude for potentially inappropriate expenditures while they generally emerge as non-significant when considering expenditures for complex medical treatments. Moreover, the separate evaluation of geographical and institutional proximity indicates that the impact of spatial effects within the same jurisdiction is larger within the same jurisdiction compared to the effects between jurisdictions. 


\section{References}

Arbia, G., Battisti, M., Di Vaio, G. (2010). "Institutions and geography: Empirical test of spatial growth models for European ", Economic Modelling, 27 (1): 12-21.

Armeni, P., Compagni A., Longo F. (2014). "Multiprofessional primary care units: What affects the clinical performance of Italian General Practitioners?", Medical Care Research and Review, 71 (4): 315-336.

Atella,V., Belotti, F., Depalo, D., Piano Mortari A. (2014). "Measuring spatial effects in the presence of institutional constraints: The case of Italian Local Health Authority expenditure", Regional Science and Urban Economics, 49: 232-241.

Balia S., Brau, R., Marrocu E. (2013). "What drives patient mobility across Italian regions? Evidence from hospital discharge data" in Levaggi R. Montefiori, M. (eds). Health care provision and patient mobility, Developments in Health Economics and Public Policy, , Vol. 12, 2014, pp 133-154.

Baltagi, B. H., Yen, Y-F. (2014). "Hospital treatment rates and spillover effects: Does ownership matter?", Regional Science and Urban Economics, 49, 193-202.

Beales S., Smith P.C. (2012). "The role of primary health care in controlling the cost of specialist health care", Nordic Economic Policy Review: 2 : 153-187.

Bech M., Lauridsen, J. (2008). “Exploring the spatial pattern in hospital admissions” Health Policy 87: 50-62.

Bech M., Lauridsen, J. (2009a). "Exploring spatial patterns in general practice expenditure”, European Journal of Health Economics 10: 243-254.

Bech M., Lauridsen, J. (2009b). "Exploring the small area variation and spatial patterns" Health Services Outcomes Research Methodology 9: 177-196.

Belotti, F., Hughes, G. Piano Mortari, A. "XSMLE: Stata module for spatial panel data models estimation".

Cappellari L., De Paoli, A., Turati, G. (2014). “Do Market Incentives in the Hospital Industry Affect Subjective Health Perceptions? Evidence from the Italian PPS-DRG Reform", IZA Discussion Paper n. 8636.

Costa-Font, J., Pons-Novell, J. (2007). "Public health expenditure and spatial interactions in a decentralized National Health System", Health Economics, 16: 291-306.

Costa-Font J., Moscone, F. (2009) "The impact of decentralization and inter-territorial interactions on Spanish health expenditure”, in Arbia G. Batagi B. (eds.) Spatial econometrics: Studies in empirical economics, Springer.

Dusheiko, M., Gravelle, H., Martin, S., Rice, N., Smith, P.C. (2011). “Does better disease management in primary care reduce hospital costs? Evidence from English primary care", Journal of Health Economics 30: 919932.

Ehlert A., Oberschachtsiek D. (2014). Does managed care reduce health care expenditure? Evidence from spatial panel data. International Journal of Health Care Finance Economics 14: 207-227.

Elhorst J.P. (2003). "Specification and Estimation of Spatial Panel Data Models", International Regional Science Review, 26: 244-268.

Elhorst J.P. (2010). "Applied Spatial Econometrics: Raising the Bar”, Spatial Economic Analysis, 5:1, 9-28.

Elhorst J.P. (2014). "Spatial Econometrics. From Cross-Sectional Data to Spatial Panels", Springer Briefs in Regional Science, Springer.

Fattore, G., Mariotti, G., Rebba, V. (2013) "Review of waiting times policies: Country case studies- Italy", in Waiting Time Policies in the Health Sector, Siciliani, L., Borowitz, M., Moran, V. (eds), OECD Health Policy Studies. 
Fiorentini, G., lezzi, E., Lippi Bruni, M., Ugolini C. (2011). "Incentives in primary care and their impact on potentially avoidable hospital admissions", European Journal of Health Economics, 12: 297-309.

Gibson, O.R., Segal L., McDermott R.A. (2013). “A systematic review of evidence on the association between hospitalisation for chronic disease related ambulatory care sensitive conditions and primary health care resourcing", BMC Health Services Research, 13: 336.

Gianonni, M., Hitris, T. (2002). "The regional impact of health care expenditure: the case of Italy". Applied Economics 34: 1829-1836.

Gravelle, H., Santos, R., Siciliani, L. (2014). “Does a hospital's quality depend on the quality of other hospitals? A spatial econometrics approach" Regional Science and Urban Economics, 49, 203-216.

lezzi, E., Lippi Bruni, M., Ugolini C. (2014). "The role of GP's compensation schemes in diabetes care: Evidence from panel data" Journal of Health Economics, 34, 104-120.

Italian Ministry of Health (2010). "Cittadini e salute: La soddisfazione degli Italiani per la sanità" (in Italian). Quaderni del Ministero della Salute, n.5.

Lacombe, D.J. (2004), “Does econometric methodology matter? An analysis of public policy using spatial econometric techniques", Geographical Analysis, 36, 105-118.

LeSage, J.P. (2014), “What regional scientists need to know about spatial econometrics", mimeo.

LeSage, J.P., Pace, R.K. (2009), "Introduction to Spatial Econometrics”, Taylor \& Francis.

Lippi Bruni, M., Nobilio, L., Ugolini C. (2008). "The analysis of a cardiological network in a regulated setting: a spatial interaction approach" Health Economics, 17, 221-233.

Lippi Bruni, M., Mammi, I., Ugolini, C. (2014). "Does the extension of primary care practice opening hours reduce the use of emergency services?", Working Paper n. 978, Department of Economics, University of Bologna.

Manski, C. F. (1993). "Identification of endogenous social effects: The reflection problem", Review of Economic Studies, 60: 531-542.

Moscone, F., Knapp, M., Tosetti E. (2007). "Mental health expenditure in England: A spatial panel approach" Journal of Health Economics, 26: 842-864.

Skinner J. (2011). "Causes and consequences of regional variations in health care”, in Pauly, M.V., McGuire T.G. and Barros, P.P. (eds), Handbook of Health Economics vol. 2, Chapter 2: 45-93, North Holland.

Wennberg J. and Gittelsohn A. (1973). "Small area variations in health care delivery", Science, 182, 1102-1108.

Yu Y., Zhang L. Li, F. Zheng X. (2013), "Strategic interaction and the determinants of public health expenditures in China: a spatial panel perspective", The Annals of Regional Science, 50: 203-221. 
Table 1- Dependent variables

\begin{tabular}{|c|c|c|c|c|c|c|c|c|c|}
\hline Dep. Var. & Definition & Mean & $\begin{array}{l}\text { St. } \\
\text { Dev. }\end{array}$ & Mean & $\begin{array}{c}\text { St. } \\
\text { Dev. }\end{array}$ & Mean & $\begin{array}{l}\text { St. } \\
\text { Dev. }\end{array}$ & Mean & $\begin{array}{l}\text { Std. } \\
\text { Dev. }\end{array}$ \\
\hline pot_inappr_exp & $\begin{array}{c}\text { Expenditures for potentially inappropriate } \\
\text { procedures (Euros per capita) }\end{array}$ & 76.33 & 9.67 & 72.29 & 9.49 & 115.68 & 14.04 & 106.61 & 12.99 \\
\hline high_compl_exp & $\begin{array}{l}\text { Expenditures for highly complex hospital } \\
\text { procedures (Euros per capita) }\end{array}$ & 246.68 & 22.69 & 242.44 & 23.15 & 232.98 & 23.64 & 233.29 & 22.81 \\
\hline Year & & \multicolumn{2}{|c|}{2007} & \multicolumn{2}{|c|}{2008} & \multicolumn{2}{|c|}{2009} & \multicolumn{2}{|c|}{2010} \\
\hline
\end{tabular}

Data are expressed in Euro per capita (residents are aged 14 or above).

Table 2 - Descriptive Statistics

\begin{tabular}{l|lrrrr}
\hline \multicolumn{1}{c|}{ Variable } & \multicolumn{1}{c}{ Definition } & Mean & St. Dev. & Min & Max \\
\hline GP_seniority & average seniority of GPs in the HD & 20.51 & 1.87 & 15.18 & 24.26 \\
share_nurse & HD share of GP practices with nurse & 9.98 & 10.13 & 0.00 & 51.22 \\
share_collaborator & HD share of GP practices with collaborator & 29.32 & 12.56 & 4.26 & 73.17 \\
share_assoc GPs & HD share of associated practices & 81.23 & 13.61 & 32.61 & 100.00 \\
share_36_50 & HD share of patients aged 36-50 & 27.91 & 1.52 & 23.60 & 31.56 \\
share_51_65 & HD share of patients aged 51-65 & 21.27 & 0.88 & 19.64 & 24.15 \\
share_over 65 & HD share of patients aged over 65 & 25.63 & 2.73 & 19.72 & 30.95 \\
share_males & HD share of male patients & 48.13 & 0.78 & 45.55 & 49.34 \\
share_foreigners & HD share of foreign patients & 7.09 & 1.75 & 2.89 & 11.60 \\
num_GP & Per-capita number of GPs in the HD & 0.000743 & 0.000059 & 0.000609 & 0.000860 \\
beds_LHA & Per-capita number of hospital beds in the LHA & 3.92 & 0.76 & 2.85 & 5.44 \\
doctors_LHA & Per-capita number of hospital doctors in the LHA & 0.002156 & 0.000214 & 0.001805 & 0.002561 \\
nurses_LHA & Per-capita number of hospital nurses in the LHA & 0.007597 & 0.000847 & 0.006504 & 0.009282 \\
clerks_LHA & Per-capita number of hospital clerks in the LHA & 0.002765 & 0.000421 & 0.002139 & 0.003667 \\
mort_LHA & LHA mortality rate & 10.78 & 1.09 & 9.03 & 12.96 \\
Income_HD & HD per-capita taxable income & 22642.97 & 2193.16 & 17911.97 & 28719.41 \\
HD wih HT & Districts with Hospital Trust (dummy) & 0.13 & 0.34 & 0.00 & 1.00 \\
HD with type A hosp & Districts with Type A hospital (dummy) & 0.21 & 0.41 & 0.00 & 1.00 \\
mountainous area & HD in totally or partially mountainous areas (dummy) & 0.13 & 0.28 & 0.00 & 1.00 \\
\hline & & & &
\end{tabular}


Table 3. Pooled OLS, FE and RE estimates of a linear panel model with no spatial effects

\begin{tabular}{|c|c|c|c|c|c|c|}
\hline \multirow[t]{2}{*}{ Dep Variable } & \multicolumn{3}{|c|}{ pot_inappr_exp } & \multicolumn{3}{|c|}{ high_compl_exp } \\
\hline & $\begin{array}{c}\text { POLS } \\
(b / s e)\end{array}$ & $\begin{array}{c}\boldsymbol{F} \boldsymbol{E} \\
(b / s e)\end{array}$ & $\begin{array}{c}\boldsymbol{R E} \\
(b / s e)\end{array}$ & $\begin{array}{c}\text { POLS } \\
(b / s e)\end{array}$ & $\begin{array}{c}\boldsymbol{F E} \\
(b / s e)\end{array}$ & $\begin{array}{c}\boldsymbol{R E} \\
(b / s e)\end{array}$ \\
\hline GP_seniority & $\begin{array}{l}-0.004 \\
(-0.148)\end{array}$ & $\begin{array}{c}-3.676 * * \\
(-1.349)\end{array}$ & $\begin{array}{c}-0.195 \\
(-0.2593)\end{array}$ & $\begin{array}{c}-0.129 \\
(-0.089))\end{array}$ & $\begin{array}{l}-2.100 * \\
(-0.8184)\end{array}$ & $\begin{array}{c}-0.168 \\
(-0.1537)\end{array}$ \\
\hline share_nurse & $\begin{array}{c}0.001 \\
(-0.0009)\end{array}$ & $\begin{array}{c}0.001 \\
(-0.0015)\end{array}$ & $\begin{array}{c}0.001 \\
(-0.0012)\end{array}$ & $\begin{array}{c}0.001^{*} \\
(-0.0005)\end{array}$ & $\begin{array}{c}-0.001 \\
(-0.0009)\end{array}$ & $\begin{array}{c}0.000 \\
(-0.0007)\end{array}$ \\
\hline share_collaborator & $\begin{array}{c}0.012 \\
(-0.0224)\end{array}$ & $\begin{array}{c}0.012 \\
(-0.0392)\end{array}$ & $\begin{array}{c}0.036 \\
(-0.0295)\end{array}$ & $\begin{array}{c}-0.023 \\
(-0.0135)\end{array}$ & $\begin{array}{c}0.02 \\
(-0.0238)\end{array}$ & $\begin{array}{c}-0.001 \\
(-0.0173)\end{array}$ \\
\hline share_assoc GPs & $\begin{array}{c}0.010 \\
(-0.0521)\end{array}$ & $\begin{array}{c}-0.075 \\
(-0.0927)\end{array}$ & $\begin{array}{c}-0.047 \\
(-0.0688)\end{array}$ & $\begin{array}{l}0.093 * * \\
(-0.0313)\end{array}$ & $\begin{array}{c}-0.009 \\
(-0.0562)\end{array}$ & $\begin{array}{c}0.037 \\
(-0.0403)\end{array}$ \\
\hline share_36_50 & $\begin{array}{c}0.505 \\
(-0.3915)\end{array}$ & $\begin{array}{c}2.726^{*} \\
(-1.1474)\end{array}$ & $\begin{array}{c}0.751 \\
(-0.6104)\end{array}$ & $\begin{array}{c}0.596 * \\
(-0.2356)\end{array}$ & $\begin{array}{c}-0.861 \\
(-0.6961)\end{array}$ & $\begin{array}{c}0.206 \\
(-0.3593)\end{array}$ \\
\hline share_51_65 & $\begin{array}{c}-0.148 \\
(-0.3614)\end{array}$ & $\begin{array}{c}0.834 \\
(-1.0721)\end{array}$ & $\begin{array}{c}-0.007 \\
(-0.5559)\end{array}$ & $\begin{array}{c}0.421 \\
(-0.2175)\end{array}$ & $\begin{array}{c}0.373 \\
(-0.6504)\end{array}$ & $\begin{array}{c}0.348 \\
(-0.3275)\end{array}$ \\
\hline share_over 65 & $\begin{array}{c}0.468 * \\
(-0.2276)\end{array}$ & $\begin{array}{c}0.316 \\
(-0.9245)\end{array}$ & $\begin{array}{c}0.713 \\
(-0.3768)\end{array}$ & $\begin{array}{c}0.674 * * * \\
(-0.137)\end{array}$ & $\begin{array}{c}0.168 \\
(-0.5609)\end{array}$ & $\begin{array}{l}0.590 * * \\
(-0.2222)\end{array}$ \\
\hline share_males & $\begin{array}{c}-0.99 \\
(-1.0127)\end{array}$ & $\begin{array}{c}3.554 \\
(-3.9976)\end{array}$ & $\begin{array}{c}-0.836 \\
(-1.7935)\end{array}$ & $\begin{array}{c}0.915 \\
(-0.6093)\end{array}$ & $\begin{array}{c}1.382 \\
(-2.4252)\end{array}$ & $\begin{array}{c}0.913 \\
(-1.0601)\end{array}$ \\
\hline share_foreigners & $\begin{array}{l}-0.061 \\
(-0.055)\end{array}$ & $\begin{array}{c}-0.018 \\
(-0.2501)\end{array}$ & $\begin{array}{c}-0.043 \\
(-0.0956)\end{array}$ & $\begin{array}{c}0.006 \\
(-0.0331)\end{array}$ & $\begin{array}{c}-0.109 \\
(-0.1517)\end{array}$ & $\begin{array}{c}0.020 \\
(-0.0565)\end{array}$ \\
\hline num_GP & $\begin{array}{l}-0.319 \\
(-0.188)\end{array}$ & $\begin{array}{l}-0.765^{*} \\
(-0.3272)\end{array}$ & $\begin{array}{c}-0.439 \\
(-0.2312)\end{array}$ & $\begin{array}{c}-0.101 \\
(-0.1131)\end{array}$ & $\begin{array}{c}0.381 \\
(-0.1985)\end{array}$ & $\begin{array}{c}0.049 \\
(-0.1351)\end{array}$ \\
\hline beds_LHA & $\begin{array}{c}-0.100 \\
(-0.1132)\end{array}$ & $\begin{array}{c}0.288 \\
(-0.3007)\end{array}$ & $\begin{array}{c}-0.243 \\
(-0.1494)\end{array}$ & $\begin{array}{l}0.148 * \\
(-0.0681\end{array}$ & $\begin{array}{c}0.130 \\
(-0.1824)\end{array}$ & $\begin{array}{c}0.070 \\
(-0.0876)\end{array}$ \\
\hline doctors_LHA & $\begin{array}{l}0.852 * * \\
(-0.2712)\end{array}$ & $\begin{array}{c}-0.566 \\
(-0.3647)\end{array}$ & $\begin{array}{c}0.288 \\
(-0.2996)\end{array}$ & $\begin{array}{c}0.337^{*} \\
(-0.1632)\end{array}$ & $\begin{array}{c}-0.133 \\
(-0.2212)\end{array}$ & $\begin{array}{c}0.093 \\
(-0.1748)\end{array}$ \\
\hline nurses_LHA & $\begin{array}{c}-0.239 \\
(-0.2722)\end{array}$ & $\begin{array}{c}1.109 * \\
(-0.5001)\end{array}$ & $\begin{array}{c}0.248 \\
(-0.3434)\end{array}$ & $\begin{array}{l}-0.350 * \\
(-0.1638)\end{array}$ & $\begin{array}{c}-0.100 \\
(-0.3034)\end{array}$ & $\begin{array}{c}-0.127 \\
(-0.2009)\end{array}$ \\
\hline clerks_LHA & $\begin{array}{c}-0.293 \\
(-0.1915)\end{array}$ & $\begin{array}{c}0.299 \\
(-0.3188)\end{array}$ & $\begin{array}{l}-0.095 \\
(-0.221)\end{array}$ & $\begin{array}{l}-0.310 * * \\
(-0.1152)\end{array}$ & $\begin{array}{c}-0.099 \\
(-0.1934)\end{array}$ & $\begin{array}{c}-0.171 \\
(-0.1293)\end{array}$ \\
\hline mort_LHA & $\begin{array}{c}0.509 * * * \\
(-0.14)\end{array}$ & $\begin{array}{c}0.747 \\
(-0.4609)\end{array}$ & $\begin{array}{c}0.413 \\
(-0.2288)\end{array}$ & $\begin{array}{c}0.438 * * * \\
(-0.0842)\end{array}$ & $\begin{array}{c}0.062 \\
(-0.2796)\end{array}$ & $\begin{array}{c}0.299 * \\
(-0.1349)\end{array}$ \\
\hline Income_HD & $\begin{array}{c}0.126 \\
(-0.1334)\end{array}$ & $\begin{array}{c}0.576 \\
(-0.905)\end{array}$ & $\begin{array}{c}0.055 \\
(-0.2439)\end{array}$ & $\begin{array}{c}-0.093 \\
(-0.0803)\end{array}$ & $\begin{array}{l}-0.405 \\
(-0.549)\end{array}$ & $\begin{array}{c}-0.034 \\
(-0.1445)\end{array}$ \\
\hline HD wih HT & $\begin{array}{c}0.021 \\
(-0.0383)\end{array}$ & & $\begin{array}{c}0.006 \\
(-0.0703)\end{array}$ & $\begin{array}{l}0.064 * * \\
(-0.0231)\end{array}$ & & $\begin{array}{c}0.039 \\
(-0.0417)\end{array}$ \\
\hline HD with type A hosp & $\begin{array}{c}0.053^{*} \\
(-0.0266)\end{array}$ & & $\begin{array}{c}0.066 \\
(-0.0489)\end{array}$ & $\begin{array}{c}0.097^{* * *} \\
(-0.016)\end{array}$ & & $\begin{array}{l}0.074^{*} \\
(-0.029)\end{array}$ \\
\hline mountainous area & $\begin{array}{c}0.238 * * * \\
(-0.047)\end{array}$ & & $\begin{array}{c}0.201^{*} \\
(-0.0873)\end{array}$ & $\begin{array}{c}-0.078 * * \\
(-0.0283)\end{array}$ & & $\begin{array}{l}-0.121 * \\
(-0.0518)\end{array}$ \\
\hline cons & $\begin{array}{c}3.436 \\
(-5.0526)\end{array}$ & $\begin{array}{c}-20.638 \\
(-21.3469)\end{array}$ & $\begin{array}{c}1.874 \\
(-9.0034)\end{array}$ & $\begin{array}{l}-6.062^{*} \\
(-3.0401)\end{array}$ & $\begin{array}{c}12.250 \\
(-12.9504)\end{array}$ & $\begin{array}{l}-2.623 \\
(-5.323)\end{array}$ \\
\hline Year dummies & Yes & Yes & Yes & Yes & Yes & Yes \\
\hline
\end{tabular}


Table 4. Estimates of the spatial autoregressive coefficient - Single Spatial Weights Matrix

\begin{tabular}{lcc|lcc}
\hline \multicolumn{2}{c|}{ Spatial } & Autoregressive Model (SAR) & \multicolumn{3}{c}{ Spatial Durbin Model (SDM) } \\
\hline $\begin{array}{l}\text { Single weight } \\
\text { matrix }\end{array}$ & \multirow{2}{*}{ pot_inappr_exp } & \multirow{2}{*}{ high_compl_exp } & $\begin{array}{l}\text { Single weight } \\
\text { matrix }\end{array}$ & pot_inappr_exp & high_compl_exp \\
\hline$\rho_{\text {ALL }}$ & $0.496^{* * *}$ & -0.039 & $\rho_{\text {ALL }}$ & $0.241^{* * *}$ & -0.120 \\
$\rho_{\text {ALL_LHA }}$ & $0.581^{* * *}$ & -0.073 & $\rho_{\text {ALL_LHA }}$ & $0.319^{* * *}$ & $-0.203^{* *}$ \\
$\rho_{\text {WI }}$ & $0.323^{* * *}$ & 0.096 & $\rho_{\text {WI }}$ & $0.322^{* * *}$ & 0.054 \\
$\rho_{\text {WI_LHA }}$ & $0.357^{* * *}$ & 0.102 & $\rho_{\text {WI_LHA }}$ & $0.320^{* * *}$ & 0.012 \\
$\rho_{\text {BE }}$ & 0.012 & -0.043 & $\rho_{\text {BE }}$ & 0.059 & $-0.122^{*}$ \\
\hline
\end{tabular}


Table 5. SAR and SDM estimation results (coefficients and spatial effects) - Single weights matrix

\begin{tabular}{|c|c|c|c|c|}
\hline & $S A R$ & $S A R$ & $S D M$ & $S D M$ \\
\hline Dep Var & pot_inappr_exp & high_compl_exp & pot_inappr_exp & high_compl_exp \\
\hline \multicolumn{5}{|l|}{ Main } \\
\hline GP_seniority & $-2.759 *$ & $-2.113^{* * *}$ & -2.152 & $-1.704 *$ \\
\hline share_nurse & 0.001 & -0.001 & 0.002 & -0.001 \\
\hline share_collaborator & 0.012 & 0.021 & 0.024 & 0.039 \\
\hline share_assoc GPs & -0.072 & -0.009 & -0.019 & 0.026 \\
\hline share_36_50 & $2.830 * *$ & -0.856 & $1.930 *$ & -0.947 \\
\hline share_51_65 & 1.018 & 0.384 & 0.165 & 0.704 \\
\hline share_over 65 & 0.67 & 0.156 & 0.398 & -0.047 \\
\hline share_males & 3.752 & 1.352 & 2.445 & 0.714 \\
\hline share_foreigners & 0.058 & -0.105 & 0.095 & -0.038 \\
\hline num_GP & $-0.603 *$ & 0.378 & $-0.695 *$ & 0.331 \\
\hline beds_LHA & 0.084 & 0.136 & -0.03 & -0.023 \\
\hline doctors_LHA & -0.517 & -0.135 & $-1.011^{*}$ & 0.191 \\
\hline nurses_LHA & 0.702 & -0.087 & 0.352 & -0.83 \\
\hline clerks_LHA & 0.368 & -0.104 & 0.613 & -0.221 \\
\hline mort_LHA & 0.478 & 0.064 & 0.323 & -0.075 \\
\hline Income_HD & 0.026 & -0.407 & -0.268 & -0.774 \\
\hline Spatial rho & $0.496 * * *$ & -0.039 & $0.241^{* *}$ & -0.12 \\
\hline \multicolumn{5}{|l|}{ Direct effects } \\
\hline GP_seniority & $-3.003^{* *}$ & $-2.131 * * *$ & $-2.285 *$ & $-1.719 *$ \\
\hline share_nurse & 0.001 & -0.001 & 0.002 & -0.001 \\
\hline share_collaborator & 0.015 & 0.021 & 0.027 & 0.036 \\
\hline share_assoc GPs & -0.079 & -0.009 & -0.009 & 0.023 \\
\hline share_36_50 & $3.254^{* * *}$ & -0.713 & $1.822 * *$ & -0.818 \\
\hline share_51_65 & 1.365 & 0.526 & 0.395 & 0.756 \\
\hline share_over 65 & 0.804 & 0.177 & 0.373 & 0.052 \\
\hline share_males & 4.164 & 1.398 & 2.909 & 0.843 \\
\hline share_foreigners & 0.065 & -0.105 & 0.054 & -0.042 \\
\hline num_GP & -0.643 & 0.378 & $-0.796 *$ & 0.334 \\
\hline beds_LHA & 0.077 & 0.147 & -0.001 & -0.015 \\
\hline doctors_LHA & -0.594 & -0.133 & $-1.036^{*}$ & 0.193 \\
\hline nurses_L̄HA & 0.759 & -0.079 & 0.398 & -0.829 \\
\hline clerks_LHA & 0.36 & -0.124 & 0.56 & -0.242 \\
\hline mort_LHA & 0.567 & 0.091 & 0.4 & -0.048 \\
\hline Income_HD & -0.062 & -0.405 & -0.123 & -0.824 \\
\hline \multicolumn{5}{|l|}{ Indirect Effects } \\
\hline GP_seniority & $-2.492 *$ & 0.083 & -2.297 & 0.216 \\
\hline share_nurse & 0.001 & 0 & 0.001 & 0 \\
\hline share_collaborator & 0.014 & -0.001 & 0.001 & $0.115^{*}$ \\
\hline share_assoc GPs & -0.069 & -0.001 & 0.211 & 0.077 \\
\hline share_36_50 & $2.658^{* *}$ & 0.017 & -5.072 & 1.452 \\
\hline share_51_65 & 1.136 & -0.027 & 1.697 & $3.178^{*}$ \\
\hline share_over 65 & 0.671 & 0.004 & -2.672 & -1.002 \\
\hline share_males & 3.528 & -0.084 & 10.932 & -4.844 \\
\hline share_foreigners & 0.051 & 0.001 & -0.792 & 0.419 \\
\hline num_GP & -0.519 & -0.016 & $-1.967 *$ & -0.236 \\
\hline beds_LHA & 0.066 & -0.012 & 0.591 & 0.195 \\
\hline doctors_LHA & -0.489 & 0.011 & 0.485 & -0.329 \\
\hline nurses_LHA & 0.607 & -0.015 & 0.197 & $1.515^{*}$ \\
\hline clerks_LHA & 0.311 & 0.011 & 0.218 & 0.359 \\
\hline mort_LHA & 0.474 & -0.004 & 1.733 & -0.248 \\
\hline Income_HD & -0.088 & 0.019 & 2.914 & -0.507 \\
\hline Total Effects & & & & \\
\hline GP_seniority & $-5.495 *$ & $-2.048 * * *$ & -4.582 & -1.503 \\
\hline share_nurse & 0.002 & -0.001 & 0.003 & 0 \\
\hline share_collaborator & 0.029 & 0.02 & 0.028 & $0.150 * *$ \\
\hline share_assoc GPs & -0.148 & -0.01 & 0.202 & 0.1 \\
\hline share_36_50 & $5.912 * * *$ & -0.696 & -3.25 & 0.634 \\
\hline share_51_65 & 2.502 & 0.499 & 2.092 & $3.934^{* *}$ \\
\hline share_over 65 & 1.475 & 0.181 & -2.299 & -0.95 \\
\hline share_males & 7.692 & 1.314 & 13.842 & -4.001 \\
\hline share_foreigners & 0.116 & -0.105 & -0.737 & 0.377 \\
\hline num_GP & $-1.162^{*}$ & 0.362 & $-2.763^{*}$ & 0.098 \\
\hline beds_LHA & 0.143 & 0.135 & 0.59 & 0.18 \\
\hline doctors_LHA & -1.083 & -0.122 & -0.551 & -0.136 \\
\hline nurses_LHA & 1.366 & -0.094 & 0.594 & 0.686 \\
\hline clerks_LHA & 0.671 & -0.113 & 0.778 & 0.117 \\
\hline mort_LHA & 1.041 & 0.087 & 2.133* & -0.296 \\
\hline Income_HD & -0.15 & -0.386 & 2.79 & -1.331 \\
\hline$W_{x}$ & & & & \\
\hline GP_seniority & & & -1.023 & 0.158 \\
\hline share_nurse & & & 0 & 0 \\
\hline share_collaborator & & & -0.008 & $0.132^{*}$ \\
\hline share_assoc GPs & & & 0.161 & 0.101 \\
\hline share_36_50 & & & $-4.333^{*}$ & 1.645 \\
\hline share_51_65 & & & 1.264 & $3.474^{*}$ \\
\hline share_over 65 & & & -2.481 & -1.195 \\
\hline share_males & & & 8.785 & -4.795 \\
\hline share_foreigners & & & -0.675 & 0.437 \\
\hline num_GP & & & $-1.399 *$ & -0.212 \\
\hline beds_LHA & & & 0.523 & 0.23 \\
\hline doctors_LHA & & & 0.727 & -0.272 \\
\hline nurses_LHA & & & 0.151 & $1.647^{* *}$ \\
\hline clerks_LHHA & & & -0.096 & 0.291 \\
\hline mort_LHA & & & 1.274 & -0.3 \\
\hline Income_HD & & & 2.691 & -0.559 \\
\hline
\end{tabular}


Table 6. Estimates of the within and between spatial autoregressive coefficient - Double Spatial Weights Matrix

\begin{tabular}{|c|c|c|c|c|c|}
\hline \multicolumn{3}{|c|}{ Spatial Autoregressive Model (SAR) } & \multicolumn{3}{|c|}{ Spatial Durbin Model (SDM) } \\
\hline $\begin{array}{l}\text { Double weight } \\
\text { Matrix }\end{array}$ & pot_inappr_exp & high_compl_exp & $\begin{array}{l}\text { Double weight } \\
\text { Matrix }\end{array}$ & pot_inappr_exp & high_compl_exp \\
\hline$\rho_{\text {WI }}$ & $0.548 * * *$ & 0.106 & $\rho_{\mathrm{WI}}$ & $0.631^{* * *}$ & -0.008 \\
\hline$\rho_{\mathrm{BE}}$ & $0.300 * * *$ & 0.003 & $\rho_{\mathrm{BE}}$ & $0.190 * * *$ & -0.033 \\
\hline$\rho_{\text {WI_LHA }}$ & $0.560 * * *$ & 0.109 & $\rho_{\text {WI_LHA }}$ & $0.611^{* * *}$ & -0.049 \\
\hline$\rho_{\mathrm{BE}_{\mathrm{L}} \mathrm{LHA}}$ & $0.303 * * *$ & 0.004 & $\rho_{\text {BE_LHA }}$ & $0.217 * * *$ & -0.070 \\
\hline
\end{tabular}


Table 7. SAR and SDM estimates - Double Spatial Weights Matrix

\begin{tabular}{|c|c|c|c|c|}
\hline \multirow[b]{2}{*}{ Dep Var } & \multicolumn{2}{|c|}{ SAR } & \multicolumn{2}{|c|}{ SDM } \\
\hline & pot_inappr_exp & high_compl_exp & pot_inappr_exp & high_compl_exp \\
\hline \multicolumn{5}{|l|}{ Main } \\
\hline GP_seniority & -0.966 & -0.564 & 2.709 & -0.458 \\
\hline share_nurse & 0.001 & 0 & 0.002 & 0 \\
\hline share_collaborator & 0.06 & 0.032 & 0.058 & 0.01 \\
\hline share_assoc GPs & -0.183 & 0.001 & -0.187 & 0.018 \\
\hline share_36_50 & 2.309 & -0.039 & $3.943 * *$ & -1.103 \\
\hline share_51_65 & 1.53 & 0.796 & 1.724 & $1.415^{*}$ \\
\hline share_over 65 & 0.978 & 0.499 & 3.096 & -0.83 \\
\hline share_males & 3.216 & 0.097 & 6.292 & 3.855 \\
\hline share_foreigners & 0.302 & -0.003 & 0.522 & -0.057 \\
\hline num_GP & -0.708 & 0.288 & -0.553 & 0.388 \\
\hline beds_LHA & 0.393 & 0.132 & 1.955 & -1.02 \\
\hline doctors_LHA & -0.078 & -0.001 & -2.505 & -0.262 \\
\hline nurses_LHA & 0.522 & 0.12 & $-11.527^{*}$ & $3.836^{*}$ \\
\hline clerks_LHA & 0.535 & -0.251 & $10.168 * * *$ & $-2.541 * *$ \\
\hline mort_L̄HA & -0.244 & -0.117 & $11.399 * * *$ & $-3.178 * * *$ \\
\hline Income_HD & -1.265 & 0.311 & -0.025 & -0.029 \\
\hline \multicolumn{5}{|l|}{ Spatial effects } \\
\hline Rho WITHIN & $0.548 * * *$ & 0.106 & $0.631 * * *$ & -0.008 \\
\hline Rho BEETWEEN & $0.300 * *$ & 0.003 & $0.190 * *$ & -0.033 \\
\hline \multicolumn{5}{|l|}{ Durbin Within } \\
\hline GP_seniority & & & -3.668 & 1.139 \\
\hline share_nurse & & & 0.002 & 0.001 \\
\hline share_collaborator & & & -0.034 & -0.059 \\
\hline share_assoc GPs & & & -0.223 & 0.101 \\
\hline share_36_50 & & & -1.295 & -0.871 \\
\hline share_51_65 & & & -1.537 & -0.304 \\
\hline share_over 65 & & & 0.288 & $-3.640 *$ \\
\hline share_males & & & 4.63 & -0.347 \\
\hline share_foreigners & & & -0.113 & -0.19 \\
\hline num_GP & & & -0.894 & -0.114 \\
\hline beds_LHA & & & -2.263 & 1.088 \\
\hline doctors_LHA & & & 2.045 & 0.283 \\
\hline nurses_L̄HA & & & $13.030 *$ & $-4.232 *$ \\
\hline clerks_LHA & & & $-9.839 * * *$ & $2.764^{* *}$ \\
\hline mort_LHA & & & $-11.566 * * *$ & $3.865^{* * *}$ \\
\hline Income_HD & & & -0.311 & $1.655^{*}$ \\
\hline \multicolumn{5}{|l|}{ Durbin Between } \\
\hline GP_seniority & & & -0.291 & -2.321 \\
\hline share_nurse & & & -0.001 & -0.001 \\
\hline share_collaborator & & & 0.038 & 0.06 \\
\hline share_assoc GPs & & & 0.004 & 0.01 \\
\hline share_36_50 & & & -0.142 & 2.216 \\
\hline share_51_65 & & & -0.66 & $3.089 *$ \\
\hline share_over 65 & & & 0.097 & 1.083 \\
\hline share_males & & & 11.035 & 1.917 \\
\hline share_foreigners & & & -0.237 & 0.384 \\
\hline num_GP & & & 0.084 & 0.155 \\
\hline beds_LHA & & & -0.367 & -0.3 \\
\hline doctors_LHA & & & $1.008^{*}$ & -0.278 \\
\hline nurses_LHA & & & 0.161 & 0.527 \\
\hline clerks_LHA & & & -0.98 & 0.206 \\
\hline mort_LHA & & & -0.463 & 0.024 \\
\hline Income_HD & & & -0.86 & -0.803 \\
\hline
\end{tabular}




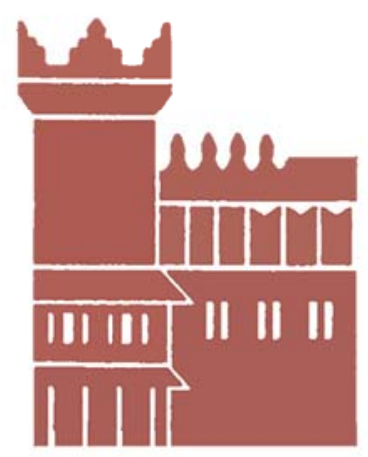

Alma Mater Studiorum - Università di Bologna DEPARTMENT OF ECONOMICS

Strada Maggiore 45

40125 Bologna - Italy

Tel. +39051 2092604

Fax +390512092664

http://www.dse.unibo.it 